\title{
A NOTE ON THE INTERTIDAL LICHEN LICHINA PYGMAEA AG.
}

\author{
By A. D. BONEY \\ Department of Chemistry and Biology, Plymouth Technical College
}

(Text-fig. I)

The shore distribution of Lichina pygmaea is now quite well known for numerous localities in the British Isles. The ecology of the lichen in the Plymouth neighbourhood has been described by Naylor (1930), Colman (1933), Evans (1947), and Southward \& Orton (1954). There is little information on other aspects of its biology, although Colman (I940) reported on the large animal population found in tufts of Lichina. The observations to be described here were made over a number of years on Lichina plants growing in the mid-littoral above M.T.L. on the east-facing side of Church Reef (= Blackstone Rocks) at Wembury, South Devon.

Experimental sites were prepared during the summer and autumn of 1952 and 1953 in order to study recolonization after clearance of the lichen. Areas of up to $150 \mathrm{~cm}^{2}$ were cleared from within the larger lichen 'mats', and half of the lichen growth removed from small circular patches. A small paint scraper was used to detach the lichen tufts, and the underlying barnacles were removed at the same time.

The cleared areas were colonized in turn by sporadic growths of green algae and by barnacles. The changes observed on one of the sites may be seen in Fig. I, which shows the site at the start of the experiment (Fig. I A, B), and then its appearance after a period of four years (Fig. I C). In one instance a limited amount of lichen growth from the borders of a cleared area was observed, but the more striking change was the retrogression in the larger 'mat'. Other changes included a localized increase in the density of the fucoid algae with an accompanying increase in the size of a lichen 'mat' where sheltered by the brown algae, and the growth of some of the smaller Lichina patches. In addition, a slight retrogression was observed in some of the Lichina growths which were not subjected to experimental treatment. The site described lay on fairly steep sloping rocks facing east. Failure of Lichina to colonize cleared areas was also observed on experimental sites prepared at the same time in 'mats' of the lichen growing on north-facing rock surfaces, but where these clearances were made no large-scale retrogression was observed.

Stages in the 'natural' retrogression of Lichina are frequently observed on 

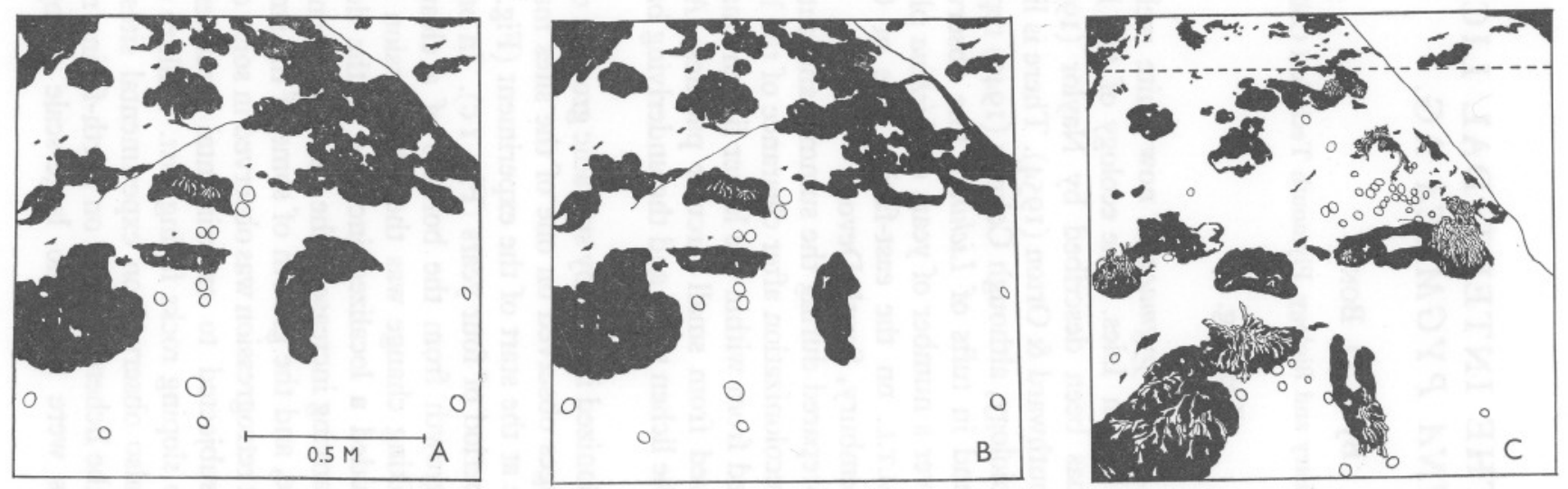

Fig. I. Diagrams (traced from photographs) of an experimental site at M.T.L. on the east-facing side of Church Reef, Wembury, South Devon. A, Appearance of the site prior to clearance of the lichen (II September I953); B, appearance immediately after three clearances of the lichen growth had been made (II September I953); C, appearance of the same site 4 years after removal of the lichen growth (13 September 1957). Photographed from a slightly different angle than in A and B. Lichina growth shown in black, and the outline of Patella shells included; the dense barnacle cover on the rest of the rock surface has been excluded. The broken line at the top of $\mathrm{C}$ represents the upper border in $\mathrm{A}$ and $\mathrm{B}$. 
the shore, and show little relation to the size of the plant growth. The early stages of the process are characterized by a change in branch colour from deep olive-green to orange-yellow, spreading from the branch tips down to the holdfast system. The centre of the 'mat' may show this condition and be surrounded by branches of normal colour. Later stages in the process result in a loss of portions of the 'mat', with stunted yellow-coloured fragments of the plant remaining isolated in the 'cleared' area. Whether this 'die-back' is a result of a particular physiological condition of the plant, or if it is caused by pathogenic organisms with further action by browsing animals, cannot be decided on present evidence. Branch tips which have borne apothecia change to orange-yellow, and some deterioration of the branches may be observed. In this condition the ends of the branches appear similar to those in which the retrogression has reached an advanced state, so that spent fruiting branches may contribute in some way to the early stages in the deterioration of parts of the lichen 'mat'.

It is possible that the act of clearance may have initiated the retrogression of Lichina shown in Fig. I. However, further evidence that this retrogression occurs in the large Lichina 'mats' under natural conditions was obtained when the lichen cover of a south-east facing rock was photographed in September 1953, and again in May 1960. Estimates were made of the Lichina cover by tracing the outline of the patches of lichen from the photographs, and then measuring the areas of clear rock face and lichen by means of squared paper. In September 1953 Lichina covered $4 \mathrm{I} \%$ of the measured rock surface. In May 1960, several of the smaller Lichina 'patches' were still recognizable, but three of the lichen 'mats' showed deterioration. However, four new Lichina patches were visible, with the result that the estimated Lichina cover in 1960 was $40 \%$ of the measured area. For this small area of the shore there was some degree of stability in the total lichen cover over the seven-year period.

This is one aspect of the ecology of Lichina which would repay further investigation, for an analysis of long-term changes would help considerably towards a better understanding of the ecological requirements of the plant. It would be necessary, however, to make observations over longer periods than those used in the present study. Within limited areas of the shore the complex of environmental factors is such that small patches of the lichen may remain unchanged for many years, but a succession of changes in shape and size be shown over the same time by a more luxuriant growth a few centimetres away; and new tufts may appear, or very small tufts show increase in size. It would be of considerable interest to know more about the early stages in the establishment and growth of a lichen tuft, and to know more about the early growth rates of tufts which attain a certain size and then appear to remain unchanged over a number of years.

Evidence has been obtained in the present work which suggests that growth of Lichina occurs in habitats where there is some degree of moisture retention 
during periods when the rock is not covered by the sea. This growth is indicated in Fig. I C; on this particular site protection by fucoid algae resulted in some increase in the area covered by the underlying Lichina. The small patches of the lichen which appeared to undergo no change in size over a considerable time interval were situated on rock surfaces above M.H.W.N.T. which drain rapidly. An instance may be given of one small roughly circular Lichina patch (diameter approximately ro $\mathrm{cm}$ ), which was cleared of half its growth in July 1952; since this time it has remained unchanged in appearance (up to May 1960).

Since growth of the lichen must have occurred in order to establish these small and apparently unchanging patches, the long-term observations envisaged above could yield useful information on growth rates. For example, it is possible that periods of growth may be linked with certain climatic cycles. Similar observations on the plant in different parts of its geographical range would be of interest, for although Lichina is found on shores exposed to fairly heavy wave action on the southern coast of the British Isles, Lewis (1957) has described its occurrence on very sheltered and unshaded shingle beaches in west Scotland, and in one instance it was observed mingled with the uppermost plants of Ascophyllum nodosum f. Mackai.

\section{SUMMARY}

Lichina pygmaea failed to recolonize areas cleared from within the lichen ' mats' after four years. A retrogression of the lichen was observed in some instances over periods of 5-7 years. A complex of factors governs the size reached by a lichen tuft; more rapid growth occurs in regions where there is some moisture retention during tidal periods. Although changes occurred with individual 'patches' of lichen, the total Lichina cover on a rocky surface remained much the same over a 7 -year period.

\section{REFERENCES}

Colman, J., 1933. The nature of the intertidal zonation of plants and animals. f. mar, biol. Ass. U.K., Vol. 18, pp. 435-76.

- 1940. On the faunas inhabiting intertidal sea-weeds. F. mar. biol. Ass. U.K., Vol. 24, pp. 129-83.

Evans, R. G., 1947. The intertidal ecology of selected localities in the Plymouth neighbourhood. F. mar. biol. Ass. U.K., Vol. 27, pp. 173-218.

LEWIS, J. R., 1957. Intertidal communities of the Northern and Western coasts of Scotland. Trans. roy. Soc. Edinb., Vol. 63, pp. 185-220.

NAYLOR, G. L., I930. Notes on the distribution of Lichina confinis and L. pygmaea in the Plymouth district. F. mar. biol. Ass. U.K., Vol. 16, pp. 909-18.

SOUTHWARD, A. J. \& ORTON, J. H., 1954. The effects of wave action on the distribution and numbers of the commoner plants and animals living on the Plymouth Breakwater. F. mar. biol. Ass. U.K., Vol. 33, pp. I-I9. 